\title{
Review Article \\ Cytokines Association with Clinical and Pathological Changes in Esophageal Squamous Cell Carcinoma
}

\author{
Dorota Diakowska \\ Department of Gastrointestinal and General Surgery, Wroclaw University of Medicine, Sklodowska-Curie 66, 50-369 Wroclaw, Poland \\ Correspondence should be addressed to Dorota Diakowska; dorota.diakowska@umed.wroc.pl
}

Received 11 September 2013; Revised 8 November 2013; Accepted 12 November 2013

Academic Editor: Xiaohong Li

Copyright (C) 2013 Dorota Diakowska. This is an open access article distributed under the Creative Commons Attribution License, which permits unrestricted use, distribution, and reproduction in any medium, provided the original work is properly cited.

\begin{abstract}
Carcinogenic transformation of cells in esophageal squamous cell carcinoma (ESCC) is characterized on molecular level by, among other things, changes in protein expression. Among all proteins related to inflammation, cytokines may be implicated as possible biological markers of esophageal cancer. These biomarkers, near imaging techniques, may be helpful in diagnosis and monitoring therapy in ESCC patients. This review demonstrates findings of researches on dysregulation of cytokines in ESCC and their clinical and pathological implications. Articles on cytokines were selected according to the following criteria: (i) the study was performed at protein level, (ii) the differences in cytokines expression or concentration were detected in tissues or serum from ESCC patients, (iii) the alterations of cytokines levels were detected by: immunohistochemistry (IHC), western blot (WB) and enzyme-linked immunosorbent assay (ELISA). Members of VEGF family seem to play an essential role as potential markers in ESCC. The results of all cytokines researches are promising but further studies are necessary to establish the biological significance of these peptydes in ESCC, their potential usefulness for early diagnosis, pre- and postoperative prognosis and monitoring of the respond to chemoand radiotherapy of cancer patients.
\end{abstract}

\section{Introduction}

Cancers of esophagus are placed among the most common malignancies worldwide, being the eighth leading cause of cancer-related deaths [1]. Esophageal squamous cell carcinoma (ESCC) is a dominant histological type of esophageal malignances $[1,2]$. This cancer is usually detected in the advanced stage of disease, when regional and/or distant metastases are presented $[2,3]$. For this reason, poor prognosis and survival prediction for ESCC patients are observed. In ESCC, dissemination of disease at diagnosis is favored by lack of serosa and rich structure of submucosal lymphatic vessels [1-3]. Because of that most ESCC patients have invisible micrometastases in tumor region at the time of diagnosis.

Surgical resection of tumor is an essential method of ESCC treatment. Then, radio- and chemotherapy are complementary methods of treatment $[4,5]$. Development of clinical observations related to such imaging techniques as endoscopy, computer tomography (CT), magnetic resonance, and positron emission tomography, helps in detection of dysplasia or neoplasia in the esophagus. These techniques are usually very accurate in the determination of methods of cancer treatment. However, it is occasionally demonstrated in the time of operation, that progression of cancer is more extensive and treatment is generally only palliative.

Two most important risk factors for ESCC are cigarette smoking and alcohol consumption [6]. They contain various chemical carcinogens, which stimulate inflammatory reactions, induce oxidative stress parameters, destabilize genome, change enzymes function, and stimulate angiogenesis [6]. In recent years, it has been demonstrated that carcinogenic transformation of cells is characterized on molecular level by, among other things, changes in protein expression [79]. These proteins can be markers of early progression of esophageal cancer. New biomarkers, near imaging techniques, may be helpful in diagnosis and monitoring therapy in ESCC patients. Identification of biological markers with the use of easy and noninvasive techniques to measure them becomes crucial. A lot of researches, conducted by methods of enzyme-linked immunosorbent assay (ELISA), western blot (WB), immunohistochemistry (IHC), and proteomic or flight-mass spectrometry approaches, detect dysregulation of 
protein level in serum and/or tumor tissues in ESCC patients. Study on relationship between protein alterations and clinical and pathological parameters can disclose the potential role of these molecules as ESCC biomarkers [7-10].

Among all proteins related to inflammation, cytokines play an important role in cancer development and progression and may be implicated as possible biological markers of esophageal cancer.

\section{Search Strategy and Criteria of Selection}

Published results for this review were found by searching of PubMed, US National Library of Medicine, and National Institute of Health (http:/www.ncbi.nlm.nih.gov/pubmed). In the search, I used the following phrases: "cytokines in esophageal squamous cell carcinoma” (110 articles), "interleukins in esophageal squamous cell carcinoma" (24 articles), "growth factors in esophageal squamous cell carcinoma" (292 articles), "esophageal squamous cell carcinoma, review" (147 articles), "cytokines in esophageal cancer, review" (67 articles), "angiogenesis in esophageal squamous cell carcinoma" (80 articles), and "VEGF in ESCC"(85 articles).

I selected articles on cytokines according to the following criteria: (i) the study was performed at protein level, (ii) the differences in cytokines expression or concentration were detected in tissues or serum from ESCC patients, and (iii) the alterations of cytokines levels were detected by immunohistochemistry (IHC), western blot (WB), and enzyme-linked immunosorbent assay (ELISA).

After selection, data from 49 articles and information about 22 cytokines related to clinicopathological parameters of ESCC patients were taken into consideration in this review.

\section{Biological Role of Cytokines and Growth Factors}

Cytokines belong to the group of soluble proteins with low molecular weight. They play a role of intercellular mediators, setting cell growth processes and participating in their differentiation, migration, and apoptosis $[11,12]$. They are secreted by many types of specific cells of the innate and adaptive immune systems. Cytokines, through their specific receptors, have an influence on a variety of cellular activities.

They play an important role in immunity, inflammation, repair, tissue homeostasis, and hematopoiesis [11]. Cytokines are characterized by pleiotropism, redundancy, synergism, and antagonism effects $[13,14]$. The group of cytokines includes currently many factors with diverse origin and various functions. Therefore, clear classification of these peptides is difficult to implement. Structurally, they include interleukins (IL), interferons (IFNs), chemokines (as IL-8), growth factors (such as tumor growth factor-beta (TGF$\beta$ ), vascular endothelial growth factor (VEGF), epidermal growth factor (EGF), and fibroblast growth factor (FGF)), tumor necrosis factor (TNF) family, hematopoietic cytokines, and others. Functionally, cytokines are divided into proinflammatory factors (such as IL-1, IL-6, IL-8, IL-18, IFN- $\gamma$, TNF- $\alpha$, TNF- $\beta$, and FasL) and anti-inflammatory factors (such as IL-4, IL-10, and TGF- $\beta$ ), [11-14].

Several inflammatory cytokines have been implicated to participate in different molecular mechanisms which lead to carcinogenesis $[14,15]$. It is common knowledge that malignant transformation process is strongly connected with the altered responses of cytokines expression [13, 15]. Cytokines play also an important role in tumorigenesis and angiogenesis stimulation and metastasis induction [13-15].

\section{Cytokines in SCC of Esophagus}

Tumor microenvironment contains not only cancerous cells, but also fibroblasts, endothelial cells, immune cells, and cytokines which play a key role in the control of communication between these types of cells [8, 12, 14-16]. Under certain conditions, in the first phase of cancer development, endogenous cytokines may stimulate host immune response against tumor cells. However, recent data indicate that the majority of these factors may induce immune dysfunctions and contribute to tumor growth, progression, metastasis, and host immunosuppression $[8,12,13]$. For this reason, alterations in microenvironment of ESCC may have a clinical significance in cancer development. As in other malignant tumors, also esophageal cancer cells suppress host immune defense by secreting a number of immunosuppressive factors $[8-10,12]$.

The cytokine network of ESCC is rich in proinflammatory cytokines, growth factors, and chemokines. I demonstrated in this study that twenty-two cytokines are associated with clinical and pathological parameters and survival rates in ESCC (Table 1). Prominent ESCC relevant cytokines are VEGF-A, VEGF-C, VEGF-D, bFGF, HGF, MIF, TGF- $\beta$, IL6, IL-8, and FasL as well as midkine, IL-18, PDGF-BB, CTGF, and CXCL12 [17-66]. High expressions of VEGF family members, HGF, bFGF, have been detected in ESCC tumor tissue, suggesting their potential role in tumor growth, angiogenesis and metastasis processes [17-53]. Also serum VEGF-A, C, D members, IL-8, IL-6, IL-18, TGF- $\beta$, HGF, FasL, PDGF-BB, and midkine concentrations were associated with tumor progression, lymph node metastasis, and distant metastasis parameters [54-66].

Probably functions of ESCC-derived cytokines are presented in Table 2. MIF is related to regulation growth processes, and IL-1 $\beta$, IL- 6 , and IL- 8 are associated with regulation transcription. IL- $1 \beta$ and IL- 6 are stimulators of proinflammatory cytokine production. FasL induces apoptosis of activated lymphocytes in host immune defense system and in consequence stimulates progression of cancer $[44,65]$. Transforming growth factor-beta (TGF- $\beta$ ) plays a dual role in the tumor development. In the early phase of carcinogenesis, this cytokine acts as a tumor suppressor, but later it is an inductor of tumor invasion by stimulation of extracellular matrix production, tumor cells proliferation, angiogenesis, and inhibition of host immune functions [42]. 


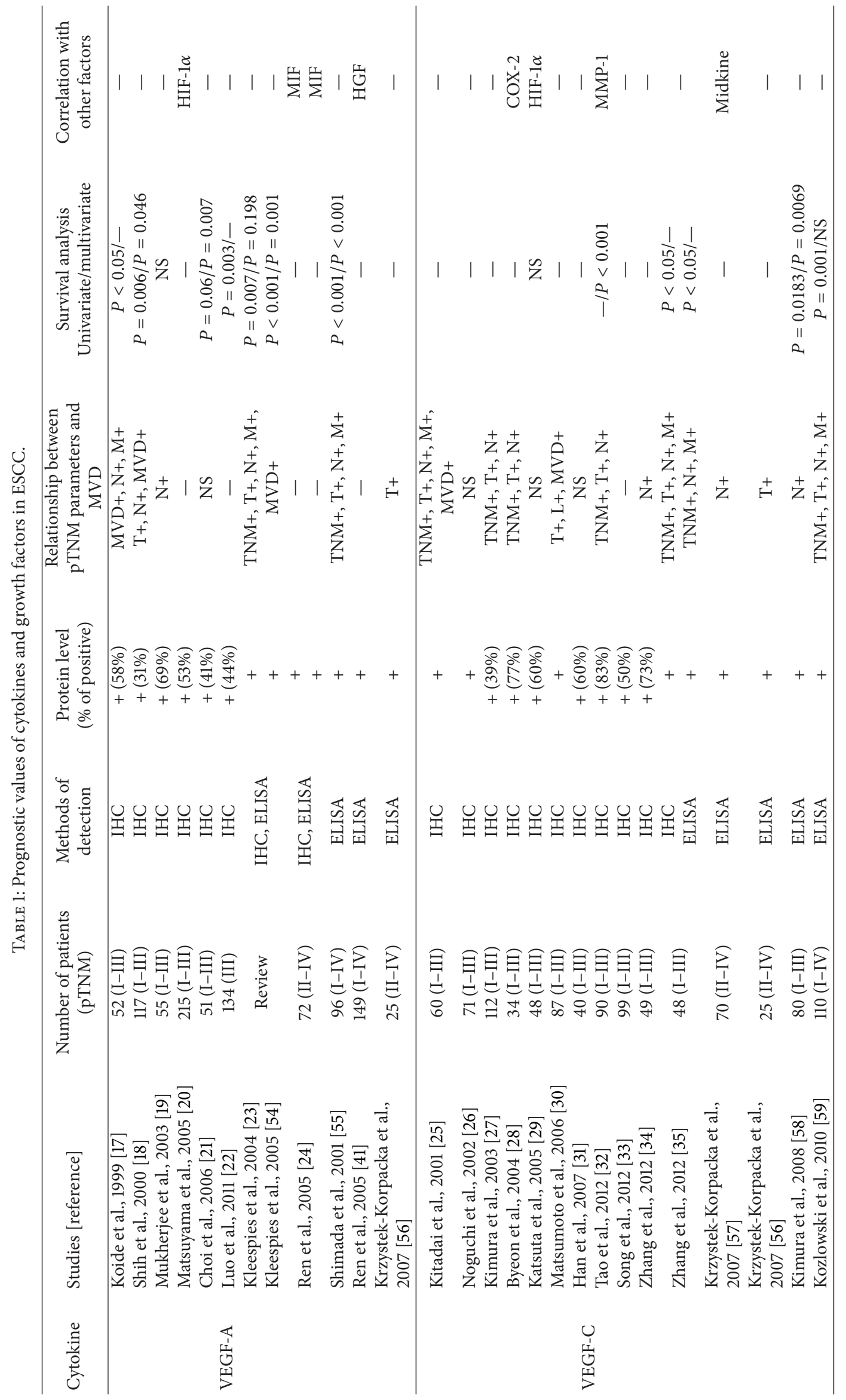




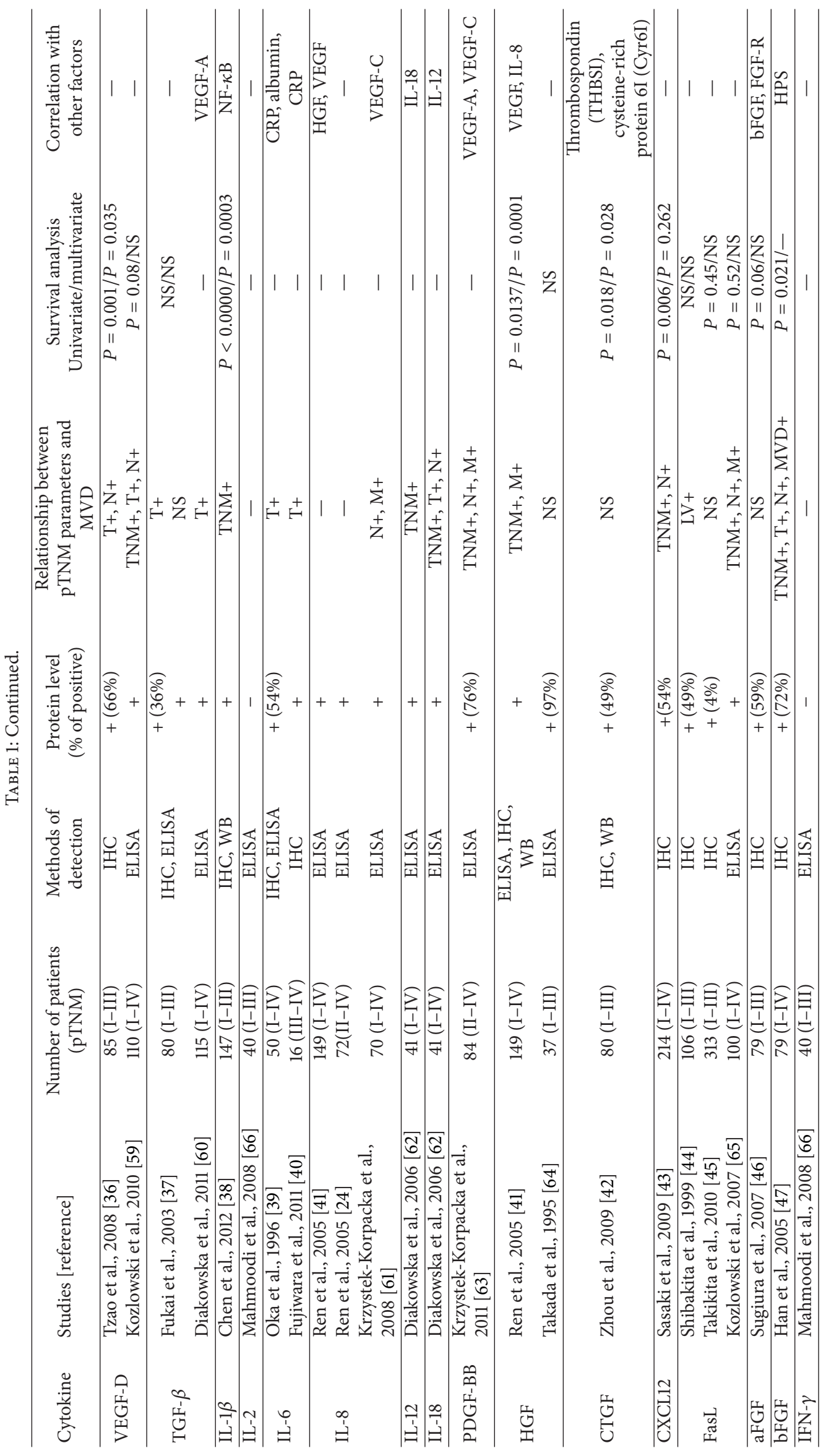




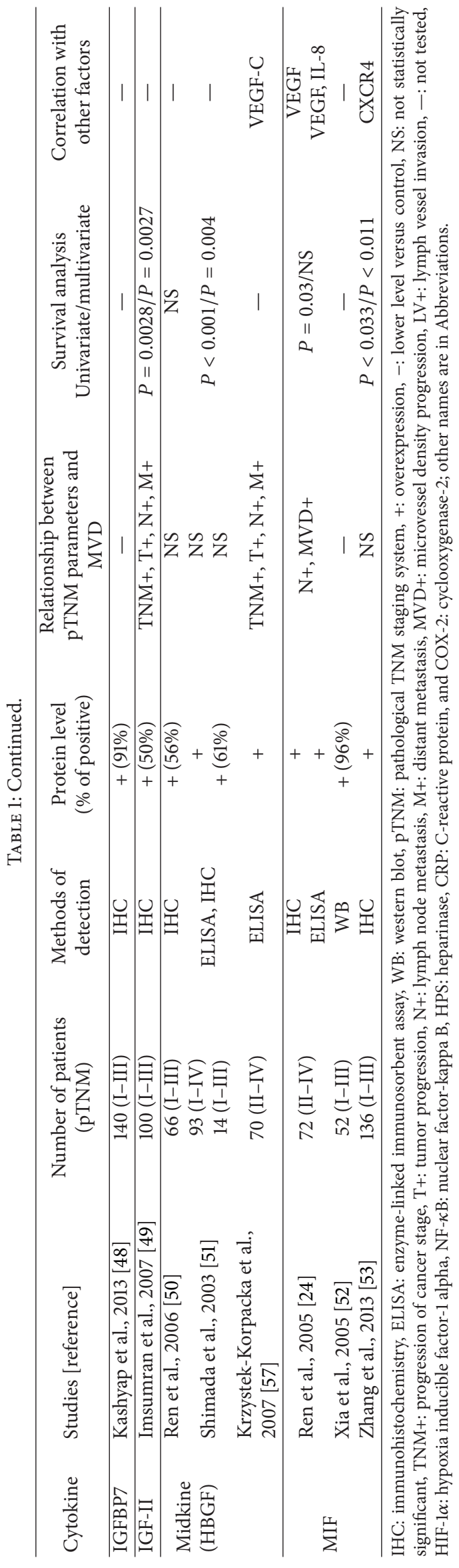


Although the majority of cytokines are known to contribute to cancer growth and metastasis, others, such as IL2, IL-12, IL-23, IL-27, and IFN- $\gamma$, may stimulate antitumor immune responses by different molecular mechanisms [67].

\section{Cytokines as Markers of ESCC Presence}

Histological changes in ESCC development include mildto-severe epithelial dysplasia, carcinoma in situ, and invasive cancer [2]. The mechanisms for the pathogenesis of esophageal cancer are still unclear. Molecular studies have revealed that genetic alterations, along with alcohol consumption and cigarette smoking, are responsible for the sequence of pathological changes in squamous epithelium of esophagus $[2,6,68,69]$. Early detection of this type of cancer may be the most useful means in effective treatment of ESCC patients. Because of that, searching for the alternations in cytokines levels, which may be associated with tumorigenesis, is necessary.

In this review, twenty-two cytokines demonstrated abnormal levels in ESCC patients (Table 1). Among these peptides, in twenty significantly higher levels [17-65] and only in IL-2 and IFN- $\gamma$-significantly lower levels [66] were reported.

Investigations with IHC studies indicated higher expression of chosen cytokines in esophageal carcinoma tissue in comparison to the normal tissue. It suggests that upregulation of these peptides is involved in tumor growth and progression. Studies on VEGF-A, VEGF-C, TGF- $\beta$, IL- $1 \beta$, IL-6, HGF, CTGF, CXCL12, FAS-L, a-FGF, bFGF, IGFBP7, IGF-II, midkine, and MIF tumor expressions have demonstrated relationship between cytokines production and cancer progression [17-53]. However, biological function of these cytokines in tumor cells and tumor microenvironment is different. On the one hand, the expression of cytokines in tumor cells promotes tumor growth and stimulates oncogenic transformation; on the other hand, production of these peptides in immune cells of tumor microenvironment may contribute also to antitumor immune response [58].

The majority of studies analyzed the expression of cytokines in tissue specimens from esophagus by using IHC method. However, these researchers examined expression of cytokines in tumor tissues both, in the early and in the advanced TNM stages of cancer. There is lack of study, which would analyze cytokines expression only in the early stage of ESCC. Absence of this type of researches is a result of high invasiveness of ESCC, and therefore there is a small group of patients with early stage of cancer.

Serum cytokines correlate positively with tumor stage, angiogenesis, and metastasis. The biological significance of circulating cytokines in esophageal cancer is currently unknown. One of the hypotheses suggests that high levels of some cytokines in serum may be related to induced apoptosis of activated lymphocytes, making facilitate tumor cells progression and metastasis easier. This inactivation of the host immune surveillance may be important for circulation of cancer cells in blood and lymph [65]. Several ELISA studies, including ours, showed significantly higher VEGF-A,
TABLE 2: Cellular functions of cytokines relevant to ESCC.

\begin{tabular}{|c|c|}
\hline Function & Cytokine [references] \\
\hline Immune suppression & TGF- $\beta[13,16,37,60]$ \\
\hline Growth regulation & $\operatorname{MIF}[13,24,52,53]$ \\
\hline Transcription regulation & $\begin{array}{l}\text { IL-1 } \beta[13,38], \\
\text { IL-6 }[39,40], \\
\text { IL-8 }[25,41,61]\end{array}$ \\
\hline $\begin{array}{l}\text { Inflammatory } \\
\text { cytokines secretion }\end{array}$ & $\begin{array}{l}\text { IL-1 } \beta[11,13,38] \\
\text { IL-6 }[11,13]\end{array}$ \\
\hline Apoptosis negative regulation & FasL $[44,45,65]$ \\
\hline $\begin{array}{l}\text { Host immune stimulation } \\
\text { (Th1 response) }\end{array}$ & $\begin{array}{l}\text { IL-2 }[66], \\
\text { IFN- } \gamma[66], \\
\text { IL-12 }[62,67], \\
\text { IL-18 }[62,67]\end{array}$ \\
\hline Angiogenesis stimulation & $\begin{array}{l}\text { VEGF-A } \\
{[7,8,13,17-24,41,54-56] \text {, }} \\
\text { VEGF-C } \\
{[7,13,25-35,56-59],} \\
\text { VEGF-D }[13,36,59], \\
\text { IL-8 }[13,24,41,61], \\
\text { HGF }[13,41,64,74], \\
\text { bFGF }[7,9,13,46,47], \\
\text { PDGF-BB }[13,63], \\
\text { MIF }[13,24,52,53]\end{array}$ \\
\hline Metastasis induction & $\begin{array}{l}\text { VEGF-A } \\
{[8,9,13,17-24,41,54-56] \text {, }} \\
\text { VEGF-C } \\
{[9,13,25-35,56-59],} \\
\text { VEGF-D }[13,36,59], \\
\text { bFGF }[13,46,47], \\
\text { HGF }[41,64,74], \\
\text { midkine }[50,51,57]\end{array}$ \\
\hline
\end{tabular}

VEGF-C, VEGF-D, TGF- $\beta$, IL-6, IL-8, IL-12, IL-18, PDGF$\mathrm{BB}, \mathrm{HGF}$, FasL, MIF, and midkine concentrations in serum of ESCC patients [54-65]. Relations between VEGF-A, VEGFC, VEGF-D, IL-12, IL-18, PDGF-BB, HGF, FasL, and midkine serum concentrations and stages of cancer progression were found [35, 37, 41, 55-65].

Analysis of IFN- $\gamma$ and IL-2 revealed strongly decreased serum level of these factors in ESCC patients [66]. Both cytokines are important inducers of Th1-associated inflammatory responses and act against cancer development [13, 66].

Based on the IHC and ELISA research, I suggest that VEGF-A, VEGF-C, and HGF could be useful biomarkers for clinical diagnosis of ESCC presence, but not for early detection of esophageal cancer [17-35, 41, 54-59, 64].

It has been observed that serum levels of VEGF-A, VEGFC, VEGF-D, and TGF- $\beta$ were elevated in ESCC patients and decreased significantly after surgical treatment $[59,60]$. The serum assay of these cytokines may be helpful for monitoring treatment efficacy in patients with ESCC.

\section{Cytokines as Proangiogenic Factors}

Angiogenesis process is essential for tumor growth and progression in ESCC [7, 13, 70-73]. A growing tumor needs 
an extensive vascular network to provide oxygen and nutrients. The construction of new intratumoral blood vessels enables cancer cells to do circulation and distant metastasis. The formation of new capillary blood vessels requires different successive steps, which are mediated and regulated by a wide range of angiogenic factors, such as proangiogenic enzymes, adhesion molecules, endothelial-specific receptors, proangiogenic cytokines, chemokines, and growth factors $[1,71-73]$.

Angiogenic factors may act directly on vascular endothelial cells, stimulating their activity, differentiation, proliferation, and migration. The following cytokines are present in ESCC : the VEGF family members, bFGF and IL-8 [7, 71].

From the above-mentioned factors, the VEGF family members seem to play the most important role in this process. VEGF-A (known also as VEGF) contributes to tumor angiogenesis and tumor growth. This growth factor protects endothelial cells from apoptosis and plays an important role in maintenance of the vascular system balance [23, 71]. In clinical studies, high expression of VEGF-A was found to be associated with tumor progression $[18,23,55,56]$, and especially, with local metastases to lymph nodes [17-19, 23, $54,55]$. Two studies showed that VEGF-A overexpression is associated with new vascular network formation $[18,23]$.

Most of researchers reported that VEGF-C and VEGF-D are implicated in the development of new lymphatic vessels [25, 27, 28, 30, 32, 34-36, 57-59]. Significant relationship between VEGF-C protein expression or serum concentration and presence of lymph node metastases was demonstrated in ten articles $[25,27,28,30,32,34,35,57-59]$. In eight articles, authors showed correlation between VEGF-C and depth of tumor invasion $[25,27,28,30,32,35,56,59]$. Significant relation between serum or tissue VEGF-D level and lymph node metastasis has been presented in two studies $[36,59]$. In these articles, authors demonstrated also the relationship between VEGF-D and stages of tumor progression. Present results suggest the possibility that cytokines forming VEGF family play a crucial role in lymphangiogenesis as independent negative prognostic factors.

Another angiogenic factor bFGF is also reported to have prognostic impact on ESCC angiogenesis. Han et al. [47] have shown by IHC study that bFGF expression is significantly associated with microvessel formation and also with primary tumor progression and lymph node metastasis.

There is also second group of cytokines, which induce proangiogenic cytokines production. These include IL- $1 \beta$, IL6, IL-8, MIF, HGF, PDGF-BB, and TGF- $\beta$.

IL- $1 \beta$, IL- 6 , and IL- 8 are important in induction of signal transduction pathway, which is involved in transcription of proangiogenic cytokines [38]. They contribute to cancer development, tumor proliferation, and metastasis [38-41, 61].

MIF can induce the secretion of angiogenic factors as VEGF-A and IL-8 in tumor, but not in normal epithelial cells. This cytokine overexpression correlates with lymph node status, tumor differentiation, microvessel density, and survival of ESCC patients and also correlates positively with VEGF-A expression [24].
Investigation on tumor tissue and serum demonstrated that HGF levels are associated with stage of cancer progression and metastasis process $[41,74]$. The study by Ren et al. [41] showed also that HGF stimulates the expression of VEGF-A, IL-8, and PDGF.

Another factor which plays a significant role in tumor development is TGF- $\beta$ [37, 60]. The study Deng et al. [75] demonstrated that TGF- $\beta$ signaling pathway is disturbed in ESCC and can contribute to tumor invasion, metastases, and patients survival. Also connective tissue growth factor (CTGF) is one of the proteins which is involved in the TGF- $\beta$ signal pathway and plays an important role in activation of angiogenesis and tumor growth [75].

In nine other studies, the increase of levels of cytokines, such as IL-12, IL-18, PDGF-BB, midkine, FasL, and IGF-II, was related to a greater depth to tumor invasion, lymph node metastasis, and higher TNM stage in ESCC patients (Table 1).

Sasaki et al. [43] reported that chemokine CXCL12 is overexpressed in ESCC and this expression is associated with the lymph node metastasis.

\section{Cytokines as Markers of Distant Metastasis}

Angiogenesis has been linked to metastasis formation, which is the principal cause of cancer mortality [71-73, 76]. Also the biological factors which are involved in metastasis often participate earlier in cell adhesion and angiogenesis processes $[9,72]$.

Neoplastic cells, which might acquire the ability to invasion and metastasis, leave primary tumor and colonize new tissue in the host body. Tumor cells use a variety of mobility mechanisms for their own changes and migration. Biochemical mediators, such as cytokines, are involved in these complex processes. Seven cytokines were related to metastasis of ESCC (Table 1). Three studies demonstrated that VEGF-A and VEGF-C overexpression may play an important role in distant migration of cancer cells [17, 25, 35] while circulating levels of VEGF-A and VEGF-C were found to be significantly elevated in patients with distant metastasis in five studies $[23,35,54,55,59]$. These results confirmed that VEGF-A and especially VEGF-C, through induction of hyperplasia of lymph vessels, are strong factors of ESCC metastasis processes. Kleespies et al. suggest that high levels of these cytokines in serum may contribute to the growth of micrometastases at distant body regions [54].

Immunohistochemistry study by Imsumran et al. revealed that high expression of IGF-II in ESCC tumor tissue correlates with lymph node and distant metastasis [49].

Findings described by Krzystek-Korpacka et al. [61, 63] demonstrated that serum IL- 8 and PDGF-BB concentrations were related to local and distant metastases.

Also levels of serum HGF correlated positively with VEGF-A and IL-8 and were associated with distant metastases [41]. Serum FasL concentration was significantly higher in ESCC patients with distant metastases, which confirmed the suggestion that FasL may induce apoptosis of activated lymphocytes, weakening host immune system and facilitating tumor metastasis. 


\section{Cytokines in Survival Prediction}

In this paper, the criteria of evaluation of cytokines as prognostic and survival markers included univariate analysis with COX proportional hazards regression model, multivariate analysis, and Kaplan-Meier method.

In univariate analysis, 13 cytokines were presented as significant prognostic factors of ESCC patients. In the multivariate analysis, 10 cytokines became ones of the prognostic factors for long-term survival, whereas levels of three cytokines did not influence patients survival (Table 1).

However, the majority of the VEGF family studies confirm that VEGF-A, VEGF-C, and VEGF-D contribute to the aggressiveness in esophageal cancer and may be useful as the strongest marker of poor outcomes in ESCC patients. Luo et al. [22] demonstrated that combined analysis of VEGF-A expression in the primary tumor and corresponding metastatic lymph nodes could help in prediction of survival of esophageal cancer patients.

As shown in Table 1, also IL-1 $\beta$, HGF, CTGF, IGF-II, and midkine are recommended as significant predictors of survival prognosis in ESCC. MIF, the cytokine expressed in cytoplasm of tumor cells and in host immune cells in tumor microenvironments, is an adverse independent factor for disease-free survival and overall survival in ESCC patients $[24,53]$.

Although various cytokines have been found to be statistically significantly associated with survival of patients, using cytokines as prognostic and survival markers for clinical decision making still remains to be evaluated with consideration of the effects of false positive and false negative issues $[77,78]$.

\section{Conclusions}

Presented articles showed that some cytokines may contribute to the aggressive characteristic of ESCC and correlate with primary tumor progression, lymph and distant metastasis, and patients outcome.

Members of VEGF family seem to play an essential role as potential early markers in ESCC. Also HGF and bFGF could serve as independent prognostic markers for ESCC. The alterations in levels of proangiogenic cytokines and growth factors such as VEGF-A, VEGF-C, TGF- $\beta$, and HGF and microvessel assessment may be used for prediction of lymphangiogenesis and distant metastasis in patients with ESCC.

Although cytokines play an important role in tumor proliferation, angiogenesis, and metastasis, their mechanism of action in ESCC is not entirely explained. Further studies are necessary to establish the biological significance of cytokines in ESCC, their potential usefulness for early diagnosis, preand postoperative prognosis, and monitoring of the response to chemo- and radiotherapy of cancer patients.

\section{Abbreviations}

ESCC: Esophageal squamous cell carcinoma VEGF-A: Vascular endothelial growth factor-A
VEGF-C: Vascular endothelial growth factor-C

VEGF-D: Vascular endothelial growth factor-D

aFGF: a fibroblast growth factor

bFGF: $\quad$ b fibroblast growth factor

TNF: Tumor necrosis factor

HGF: Hepatocyte growth factor

MIF: $\quad$ Migration inhibitory factor

TGF- $\beta$ : $\quad$ Tumor growth factor-beta

IL-1 $\beta$ : Interleukin-1 $\beta$

IL-2: $\quad$ Interleukin-2

IL-6: $\quad$ Interleukin-6

IL-8: $\quad$ Interleukin-8

IL-12: Interleukin-12

IL-18: Interleukin-18

FasL: $\quad$ Fas ligand

IFN- $\gamma$ : Interferon- $\gamma$

IGFBP7: Insulin-like growth factor-binding protein 7

IGF-II: Insulin growth factor II

HBGF: Heparin-binding growth factor (midkine)

PDGF-BB: Platelet-derived growth factor

CTGF: Connective tissue growth factor

CXCL12: Stromal cell-derived factor 1.

\section{References}

[1] C. M. Valverde, T. Macarulla, E. Casado, F. J. Ramos, E. Martinelli, and J. Tabernero, "Novel targets in gastric and esophageal cancer," Critical Reviews in Oncology/Hematology, vol. 59, no. 2, pp. 128-138, 2006.

[2] H. Kuwano, M. Nakajima, T. Miyazaki, and H. Kato, "Distinctive clinicopathological characteristics in esophageal squamous cell carcinoma," Annals of Thoracic and Cardiovascular Surgery, vol. 9, no. 1, pp. 6-13, 2003.

[3] Y. Kumagai, M. Toi, K. Kawada, and T. Kawano, "Angiogenesis in superficial esophageal squamous cell carcinoma: magnifying endoscopic observation and molecular analysis," Digestive Endoscopy, vol. 22, no. 4, pp. 259-267, 2010.

[4] C. Mariette, G. Piessen, and J.-P. Triboulet, "Therapeutic strategies in oesophageal carcinoma: role of surgery and other modalities," The Lancet Oncology, vol. 8, no. 6, pp. 545-553, 2007.

[5] B. Bystricky, A. F. C. Okines, and D. Cunningham, "Optimal therapeutic strategies for resectable oesophageal or oesophagogastric junction cancer," Drugs, vol. 71, no. 5, pp. 541-555, 2011.

[6] H. Messmann, "Squamous cell cancer of the oesophagus," Best Practice and Research, vol. 15, no. 2, pp. 249-265, 2001.

[7] D. Vallböhmer, J. Brabender, R. Metzger, and A. H. Hölscher, "Genetics in the pathogenesis of esophageal cancer: possible predictive and prognostic factors," Journal of Gastrointestinal Surgery, vol. 14, no. 1, supplement, pp. S75-S80, 2010.

[8] J. Liu, Z. Li, J. Cui, G. Xu, and G. Cui, "Cellular changes in the tumor microenvironment of human esophageal squamous cell carcinomas," Tumour Biology, vol. 33, no. 2, pp. 495-505, 2012.

[9] D.-C. Lin, X.-L. Du, and M.-R. Wang, "Protein alterations in ESCC and clinical implications: a review," Diseases of the Esophagus, vol. 22, no. 1, pp. 9-20, 2009.

[10] S.-Y. Xu, Z. Liu, W.-J. Ma, I. Sheyhidin, S.-T. Zheng, and X.-M. $\mathrm{Lu}$, "New potential biomarkers in the diagnosis of esophageal 
squamous cell carcinoma," Biomarkers, vol. 14, no. 5, pp. 340346, 2009.

[11] M. Chechlińska, "Rola cytokin w procesach nowotworzenia. Article in Polish," Journal of Oncology, vol. 536, pp. 648-659, 2003.

[12] J. Wilson and F. Balkwill, "The role of cytokines in the epithelial cancer microenvironment," Seminars in Cancer Biology, vol. 12, no. 2, pp. 113-120, 2002.

[13] R. Pries and B. Wollenberg, "Cytokines in head and neck cancer," Cytokine and Growth Factor Reviews, vol. 17, no. 3, pp. 141-146, 2006.

[14] Z. Serefoglou, C. Yapijakis, E. Nkenke, and E. Vairaktaris, "Genetic association of cytokine DNA polymorphisms with head and neck cancer," Oral Oncology, vol. 44, no. 12, pp. 10931099, 2008.

[15] N. Eiro and J. Visoso, "Imflammation and cancer," World Journal of Gastrointestinal Surgery, vol. 4, no. 3, pp. 62-72, 2012.

[16] K. Noma, K. S. M. Smalley, M. Lioni et al., "The essential role of fibroblasts in esophageal squamous cell carcinoma-induced angiogenesis," Gastroenterology, vol. 134, no. 7, pp. 1981-1993, 2008.

[17] N. Koide, A. Nishio, T. Kono et al., "Histochemical study of vascular endothelial growth factor in squamous cell carcinoma of the esophagus," Hepato-Gastroenterology, vol. 46, no. 26, pp. 952-958, 1999.

[18] C.-H. Shih, S. Ozawa, N. Ando, M. Ueda, and M. Kitajima, "Vascular endothelial growth factor expression predicts outcome and lymph node metastasis in squamous cell carcinoma of the esophagus," Clinical Cancer Research, vol. 6, no. 3, pp. 1161-1168, 2000.

[19] T. Mukherjee, A. Kumar, M. Mathur, T. K. Chattopadhyay, and R. Ralhan, "Ets-1 and VEGF expression correlates with tumor angiogenesis, lymph node metastasis, and patient survival in esophageal squamous cell carcinoma," Journal of Cancer Research and Clinical Oncology, vol. 129, no. 7, pp. 430-436, 2003.

[20] T. Matsuyama, K. Nakanishi, T. Hayashi et al., "Expression of hypoxia-inducible factor- $1 \alpha$ in esophageal squamous cell carcinoma," Cancer Science, vol. 96, no. 3, pp. 176-182, 2005.

[21] J. Y. Choi, K.-T. Jang, Y. M. Shim et al., "Prognostic significance of vascular endothelial growth factor expression and microvessel density in esophageal squamous cell carcinoma: comparison with positron emission tomography," Annals of Surgical Oncology, vol. 13, no. 8, pp. 1054-1062, 2006.

[22] K.-J. Luo, Y. Hu, J. Wen, and J.-H. Fu, "CyclinD1, p53, Ecadherin, and VEGF discordant expression in paired regional metastatic lymph nodes of esophageal squamous cell carcinoma: a tissue array analysis," Journal of Surgical Oncology, vol. 104, no. 3, pp. 236-243, 2011.

[23] A. Kleespies, M. Guba, K.-W. Jauch, and C. J. Bruns, "Vascular endothelial growth factor in esophageal cancer," Journal of Surgical Oncology, vol. 87, no. 2, pp. 95-104, 2004.

[24] Y. Ren, S. Law, X. Huang et al., "Macrophage migration inhibitory factor stimulates angiogenic factor expression and correlates with differentiation and lymph node status in patients with esophageal squamous cell carcinoma," Annals of Surgery, vol. 242, no. 1, pp. 55-63, 2005.

[25] Y. Kitadai, T. Amioka, K. Haruma et al., "Clinicopathological significance of vascular endothelial growth factor (VEGF)-C in human esophageal squamous cell carcinomas," International Journal of Cancer, vol. 93, no. 5, pp. 662-666, 2001.
[26] T. Noguchi, S. Takeno, T. Shibata, Y. Uchida, S. Yokoyama, and W. Müller, "VEGF-C expression correlates with histological differentiation and metastasis in squamous cell carcinoma of the esophagus," Oncology Reports, vol. 9, no. 5, pp. 995-999, 2002.

[27] Y. Kimura, M. Watanabe, T. Ohga et al., "Vascular endothelial growth factor $\mathrm{C}$ expression correlates with lymphatic involvement and poor prognosis in patients with esophageal squamous cell carcinoma," Oncology Reports, vol. 10, no. 6, pp. 1747-1751, 2003.

[28] J.-S. Byeon, H.-Y. Jung, Y. J. Lee et al., "Clinicopathological significance of vascular endothelial growth factor- $\mathrm{C}$ and cyclooxygenase-2 in esophageal squamous cell carcinoma," Journal of Gastroenterology and Hepatology, vol. 19, no. 6, pp. 648-654, 2004.

[29] M. Katsuta, M. Miyashita, H. Makino et al., "Correlation of hypoxia inducible factor- $1 \alpha$ with lymphatic metastasis via vascular endothelial growth factor- $\mathrm{C}$ in human esophageal cancer," Experimental and Molecular Pathology, vol. 78, no. 2, pp. 123-130, 2005.

[30] M. Matsumoto, S. Natsugoe, H. Okumura et al., "Overexpression of vascular endothelial growth factor-C correlates with lymph node micrometastasis in submucosal esophageal cancer," Journal of Gastrointestinal Surgery, vol. 10, no. 7, pp. 1016-1022, 2006.

[31] Ü. Han, O. I. Can, S. Han, B. Kayhan, and B. U. Onal, "Expressions of p53, VEGF C, p21: could they be used in preoperative evaluation of lymph node metastasis of esophageal squamous cell carcinoma?" Diseases of the Esophagus, vol. 20, no. 5, pp. 379-385, 2007.

[32] Y. S. Tao, X. Y. Ma, D. M. Chai et al., "Overexpression of MMP1 and VEGF-C is associated with a less favorable prognosis in esophageal squamous cell carcinoma," Onkologie, vol. 35, no. 11, pp. 651-656, 2012.

[33] Y. Song, Z. Wang, X. Liu, W. Jiang, and M. Shi, "CCR7 and VEGF-C: molecular indicator of lymphatic metastatic recurrence in pN0 esophageal squamous cell carcinoma after IvorLewis esophagectomy?" Annals of Surgical Oncology, vol. 19, no. 11, pp. 3606-3612, 2012.

[34] H. Zhang, Y. Yin, L. Zhang et al., "The effects of vascular endothelial growth factor $\mathrm{C}$ knockdown in esophageal squamous cell carcinoma," Journal of Cancer Research and Clinical Oncology, vol. 138, no. 1, pp. 133-139, 2012.

[35] W. Zhang, M. Zhang, B. Zhou, Z. Jia, Z. Qiao, and J. Zhang, "Expression and significance of vascular endothelial growth factor $\mathrm{C}$ from multiple specimen sources in esophageal squamous cell carcinoma," The International Journal of Biological Markers, vol. 27, no. 4, pp. e359-e365, 2012.

[36] C. Tzao, S.-C. Lee, H.-J. Tung et al., "Expression of hypoxiainducible factor (HIF)- $1 \alpha$ and vascular endothelial growth factor (VEGF)-D as outcome predictors in resected esophageal squamous cell carcinoma," Disease Markers, vol. 25, no. 3, pp. 141-148, 2008.

[37] Y. Fukai, M. Fukuchi, N. Masuda et al., "Reduced expression of transforming growth factor- $\beta$ receptors is an unfavorable prognostic factor in human esophageal squamous cell carcinoma," International Journal of Cancer, vol. 104, no. 2, pp. 161-166, 2003.

[38] M.-F. Chen, M.-S. Lu, P.-T. Chen, W.-C. Chen, P.-Y. Lin, and K.-D. Lee, "Role of interleukin 1 beta in esophageal squamous cell carcinoma," Journal of Molecular Medicine, vol. 90, no. 1, pp. 89-100, 2012. 
[39] M. Oka, K. Yamamoto, M. Takahashi et al., "Relationship between serum levels of interleukin 6, various disease parameters, and malnutrition in patients with esophageal squamous cell carcinoma," Cancer Research, vol. 56, no. 12, pp. 2776-2780, 1996.

[40] H. Fujiwara, K. Suchi, S. Okamura et al., "Elevated serum CRP levels after induction chemoradiotherapy reflect poor treatment response in association with IL-6 in serum and local tumor site in patients with advanced esophageal cancer," Journal of Surgical Oncology, vol. 103, no. 1, pp. 62-68, 2011.

[41] Y. Ren, B. Cao, S. Law et al., "Hepatocyte growth factor promotes cancer cell migration and angiogenic factors expression: a prognostic marker of human esophageal squamous cell carcinomas," Clinical Cancer Research, vol. 11, no. 17, pp. 6190-6197, 2005.

[42] Z.-Q. Zhou, W.-H. Cao, J.-J. Xie et al., "Expression and prognostic significance of THBS1, Cyr61 and CTGF in esophageal squamous cell carcinoma," BMC Cancer, vol. 9, article 291, 2009.

[43] K. Sasaki, S. Natsugoe, S. Ishigami et al., "Expression of CXCL12 and its receptor CXCR4 in esophageal squamous cell carcinoma," Oncology Reports, vol. 21, no. 1, pp. 65-71, 2009.

[44] M. Shibakita, M. Tachibana, D. K. Dhar et al., "Prognostic significance of Fas and Fas ligand expressions in human esophageal cancer," Clinical Cancer Research, vol. 5, no. 9, pp. 2464-2469, 1999.

[45] M. Takikita, N. Hu, J. Z. Shou, Q. H. Wang, C. Giffen, P. R. Taylor et al., "Lack of Fas-pathway gene mutations in primary resected esophageal squamous cell carcinoma," Chang Gung Medical Journal, vol. 33, no. 2, pp. 145-151, 2010.

[46] K. Sugiura, S. Ozawa, Y. Kitagawa, M. Ueda, and M. Kitajima, "Co-expression of aFGF and FGFR-1 is predictive of a poor prognosis in patients with esophageal squamous cell carcinoma," Oncology Reports, vol. 17, no. 3, pp. 557-564, 2007.

[47] B. Han, J. Liu, M.-J. Ma, and L. Zhao, "Clinicopathological significance of heparanase and basic fibroblast growth factor expression in human esophageal cancer," World Journal of Gastroenterology, vol. 11, no. 14, pp. 2188-2192, 2005.

[48] M. K. Kashyap, H. A. Pawar, S. Keerthikumar, J. Sharma, R. Goel, R. Mahmood et al., "Evaluation of protein expression pattern of stanniocalcin 2, insulin-like growth factor-binding protein 7, inhibin beta $\mathrm{A}$ and four and a half LIM domains 1 in esophageal squamous cell carcinoma," Cancer Biomark, vol. 12, no. 1, pp. 1-9, 2013.

[49] A. Imsumran, Y. Adachi, H. Yamamoto et al., "Insulin-like growth factor-I receptor as a marker for prognosis and a therapeutic target in human esophageal squamous cell carcinoma," Carcinogenesis, vol. 28, no. 5, pp. 947-956, 2007.

[50] Y.-J. Ren and Q.-Y. Zhang, "Expression of midkine and its clinical significance in esophageal squamous cell carcinoma," World Journal of Gastroenterology, vol. 12, no. 13, pp. 2006-2010, 2006.

[51] H. Shimada, Y. Nabeya, S.-I. Okazumi et al., "Increased serum midkine concentration as a possible tumor marker in patients with superficial esophageal cancer," Oncology Reports, vol. 10, no. 2, pp. 411-414, 2003.

[52] H. H.-X. Xia, S. T. Zhang, S. K. Lam, M. C.-M. Lin, H. F. Kung, and B. C.-Y. Wong, "Expression of macrophage migration inhibitory factor in esophageal squamous cell carcinoma and effects of bile acids and NSAIDs," Carcinogenesis, vol. 26, no. 1, pp. 11-15, 2005.

[53] L. Zhang, S. B. Ye, G. Ma, X. F. Tang, S. P. Chen, J. He et al., “The expressions of MIF and CXCR4 protein in tumor microenvironment are adverse prognostic factors in patients with esophageal squamous cell carcinoma," Journal of Translational Medicine, vol. 11, article 60, 2013.

[54] A. Kleespies, C. J. Bruns, and K.-W. Jauch, "Clinical significance of VEGF-A, -C and -D expression in esophageal malignancies," Onkologie, vol. 28, no. 5, pp. 281-288, 2005.

[55] H. Shimada, A. Takeda, Y. Nabeya, S. Okazumi, H. Matsubara, Y. Funami et al., "Clinical significance of serum vascular endothelial growth factor in esophageal squamous cell carcinoma," Cancer, vol. 92, pp. 663-669, 2001.

[56] M. Krzystek-Korpacka, M. Matusiewicz, D. Diakowska, K. Grabowski, K. Blachut, and T. Banas, "Up-regulation of VEGF$\mathrm{C}$ secreted by cancer cells and not VEGF-A correlates with clinical evaluation of lymph node metastasis in esophageal squamous cell carcinoma (ESCC)," Cancer Letters, vol. 249, no. 2, pp. 171-177, 2007.

[57] M. Krzystek-Korpacka, M. Matusiewicz, D. Diakowska et al., "Serum midkine depends on lymph node involvement and correlates with circulating VEGF-C in oesophageal squamous cell carcinoma," Biomarkers, vol. 12, no. 4, pp. 403-413, 2007.

[58] H. Kimura, H. Kato, N. Tanaka et al., "Preoperative serum vascular endothelial growth factor-C (VEGF-C) levels predict recurrence in patients with esophageal cancer," Anticancer Research, vol. 28, no. 1A, pp. 165-170, 2008.

[59] M. Kozlowski, O. Kowalczuk, R. Milewski, L. Chyczewski, J. Niklinski, and J. Laudański, "Serum vascular endothelial growth factors C and D in patients with oesophageal cancer," European Journal of Cardio-Thoracic Surgery, vol. 38, no. 3, pp. 260-267, 2010.

[60] D. Diakowska, A. Lewandowski, K. Markocka-Mczka, and K. Grabowski, "Elevated levels of serum transforming growth factor- $\beta 1$ in oesophageal squamous cell carcinoma patients," Wspolczesna Onkologia, vol. 15, no. 3, pp. 137-141, 2011.

[61] M. Krzystek-Korpacka, M. Matusiewicz, D. Diakowska et al., "Elevation of circulating interleukin-8 is related to lymph node and distant metastases in esophageal squamous cell carcinomas-Implication for clinical evaluation of cancer patient," Cytokine, vol. 41, no. 3, pp. 232-239, 2008.

[62] D. Diakowska, K. Markocka-Mçcka, K. Grabowski, and A. Lewandowski, "Serum interleukin-12 and interleukin-18 levels in patients with oesophageal squamous cell carcinoma," Experimental Oncology, vol. 28, no. 4, pp. 319-322, 2006.

[63] M. Krzystek-Korpacka, D. Diakowska, A. Gamian, and M. Matusiewicz, "Increase in serum Platelet-Derived Growth Factor (PDGF)-BB reflects lymph node involvement in esophageal cancer patients independently from platelet count," Experimental Oncology, vol. 33, no. 3, pp. 140-144, 2011.

[64] N. Takada, Y. Yano, T. Matsuda et al., "Expression of immunoreactive human hepatocyte growth factor in human esophageal squamous cell carcinomas," Cancer Letters, vol. 97, no. 2, pp. 145-148, 1995.

[65] M. Kozłowski, O. Kowalczuk, A. Sulewska et al., "Serum soluble Fas ligand (sFasL) in patients with primary squamous cell carcinoma of the esophagus," Folia Histochemica et Cytobiologica, vol. 45, no. 3, pp. 199-204, 2007.

[66] M. Mahmoodi, M.-R. Mir, P. Daryaei et al., "Cytokine response following transthoracic and transhiatal esophagectomy in patients with esophageal cancer," European Cytokine Network, vol. 19, no. 2, pp. 92-98, 2008.

[67] T. Yoshimoto, M. Xu, I. Mizoguchi, N. Morishima, Y. Chiba, and J. Mizuguchi, "Regulation of antitumor immune responses by the IL-12 family cytokines, IL-12, IL-23, and IL-27," Clinical 
and Developmental Immunology, vol. 2010, Article ID 832454, 9 pages, 2010.

[68] A. K. Lam, "Molecular biology of esophageal squamous cell carcinoma," Critical Reviews in Oncology/Hematology, vol. 33, pp. 71-90, 2000.

[69] J. Szumiło, "Epidemiology and risk factors of the esophageal squamous cell carcinoma," Polski Merkuriusz Lekarski, vol. 26, no. 151, pp. 82-85, 2009.

[70] Y. Oshima, S. Yajima, K. Yamazaki, K. Matsushita, M. Tagawa, and H. Shimada, "Angiogenesis-related factors are molecular targets for diagnosis and treatment of patients with esophageal carcinoma," Annals of Thoracic and Cardiovascular Surgery, vol. 16, no. 6, pp. 389-393, 2010.

[71] S. Liekens, E. De Clercq, and J. Neyts, "Angiogenesis: regulators and clinical applications," Biochemical Pharmacology, vol. 61, no. 3, pp. 253-270, 2001.

[72] T. D. Tsirlis, G. Papastratis, K. Masselou et al., "Circulating lymphangiogenic growth factors in gastrointestinal solid tumors, could they be of any clinical significance?" World Journal of Gastroenterology, vol. 14, no. 17, pp. 2691-2701, 2008.

[73] Y. Kubota, K. Kaneko, K. Konishi et al., "The onset of angiogenesis in a multistep process of esophageal squamous cell carcinoma," Frontiers in Bioscience, vol. 14, no. 10, pp. 38723878, 2009.

[74] K. D. Grugan, C. G. Miller, Y. Yao et al., "Fibroblast-secreted hepatocyte growth factor plays a functional role in esophageal squamous cell carcinoma invasion," Proceedings of the National Academy of Sciences of the United States of America, vol. 107, no. 24, pp. 11026-11031, 2010.

[75] Y.-Z. Deng, P.-P. Chen, Y. Wang et al., "Connective tissue growth factor is overexpressed in esophageal squamous cell carcinoma and promotes tumorigenicity through $\beta$-catenin-Tcell factor/Lef signaling," Journal of Biological Chemistry, vol. 282, no. 50, pp. 36571-36581, 2007.

[76] A. Ooki, K. Yamashita, N. Kobayashi et al., "Lymph node metastasis density and growth pattern as independent prognostic factors in advanced esophageal squamous cell carcinoma," World Journal of Surgery, vol. 31, no. 11, pp. 2184-2191, 2007.

[77] M. S. Pepe, H. Janes, G. Longton, W. Leisenring, and P. Newcomb, "Limitations of the odds ratio in gauging the performance of a diagnostic, prognostic, or screening marker," American Journal of Epidemiology, vol. 159, no. 9, pp. 882-890, 2004.

[78] M. S. Pepe, K. F. Kerr, G. Longton, and Z. Wang, "Testing for improvement in prediction model performance," Statistics in Medicine, vol. 32, no. 9, pp. 1467-1482, 2013. 


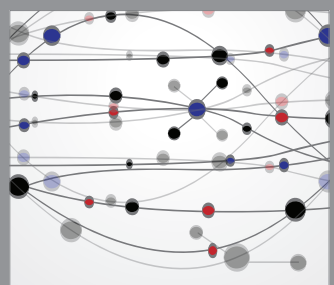

The Scientific World Journal
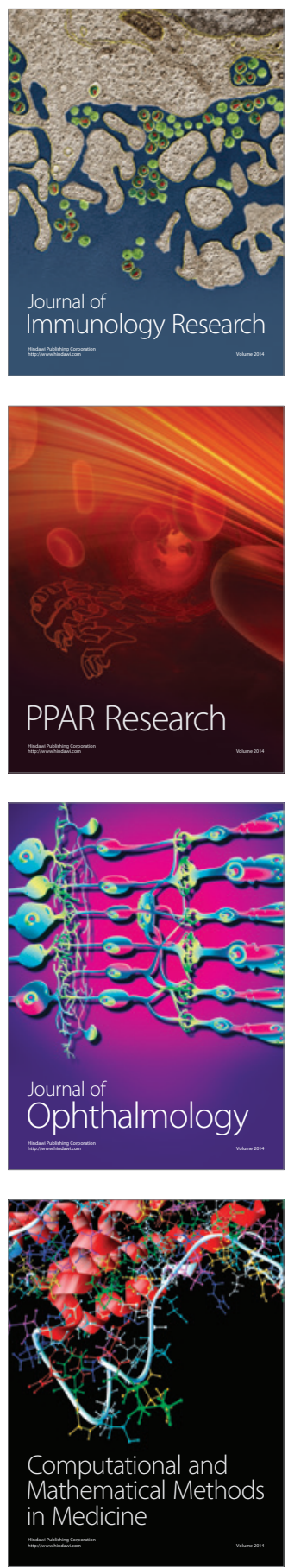

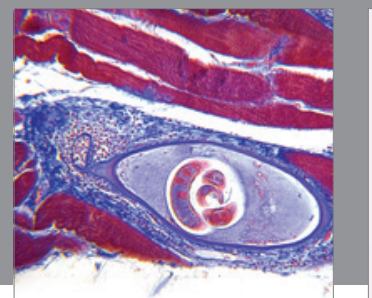

Gastroenterology

Research and Practice
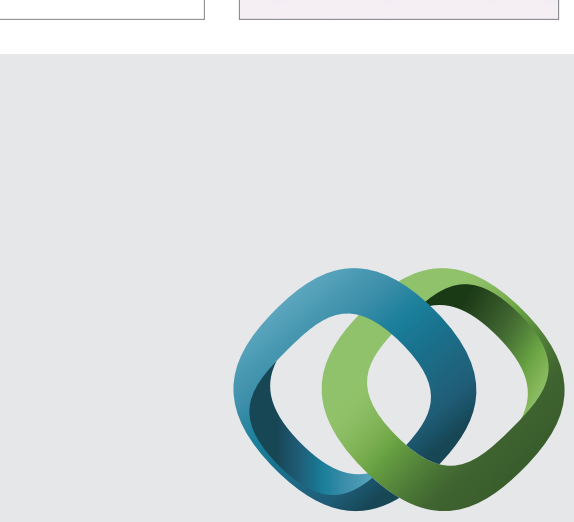

\section{Hindawi}

Submit your manuscripts at

http://www.hindawi.com
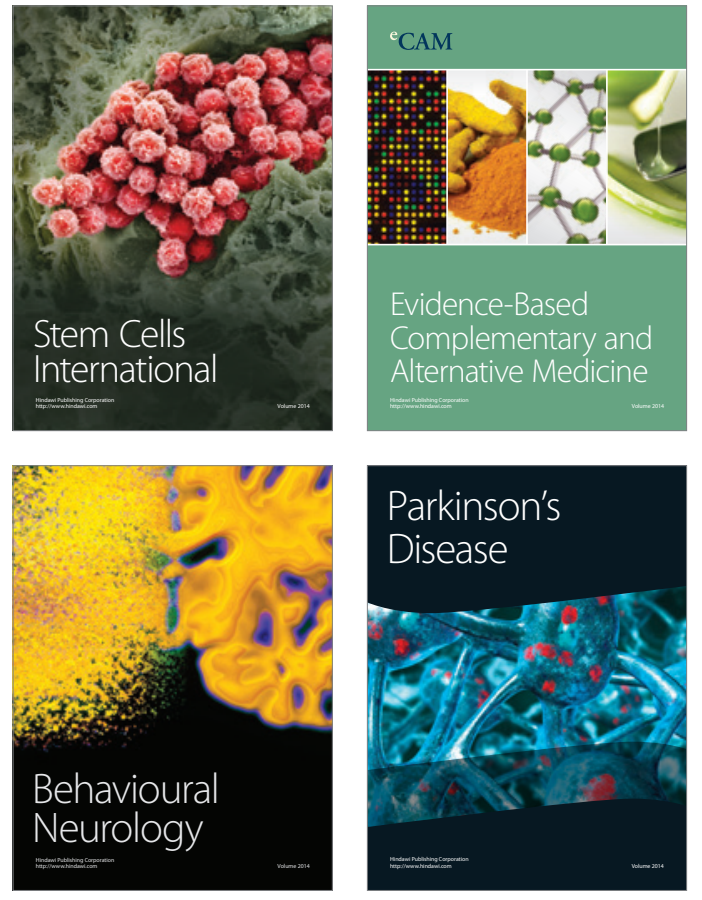
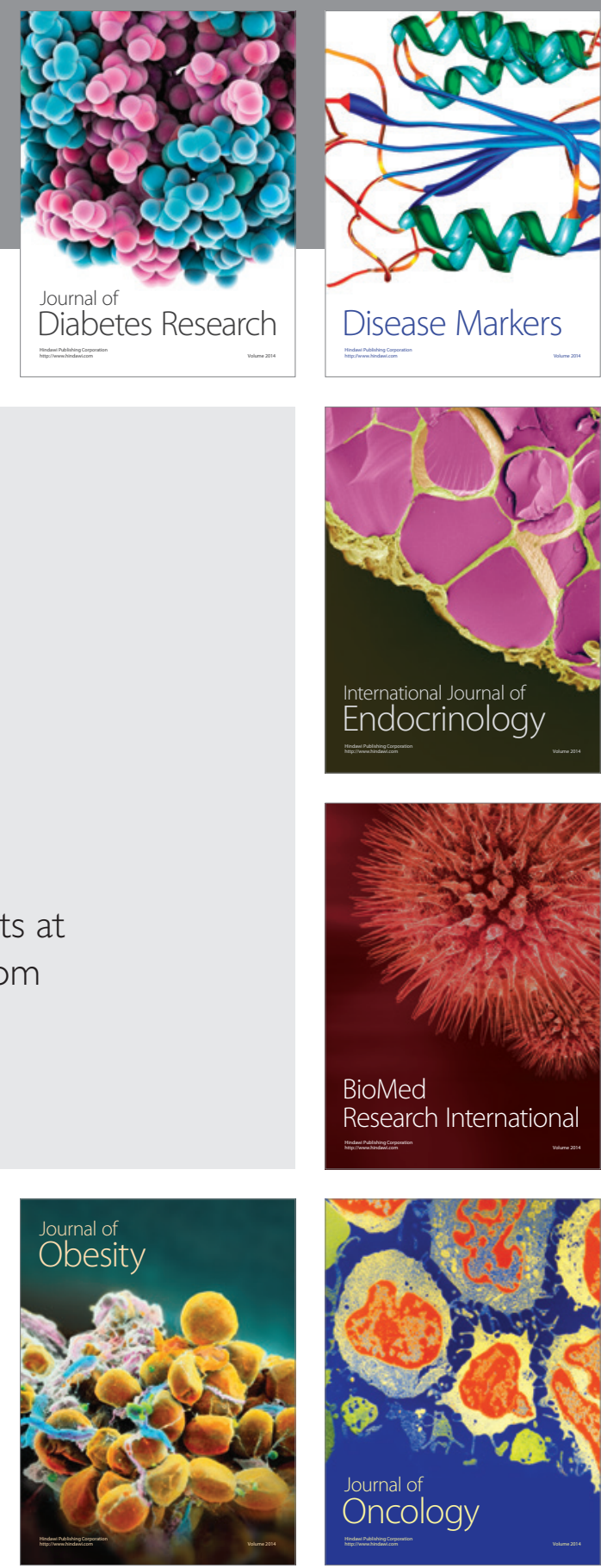

Disease Markers
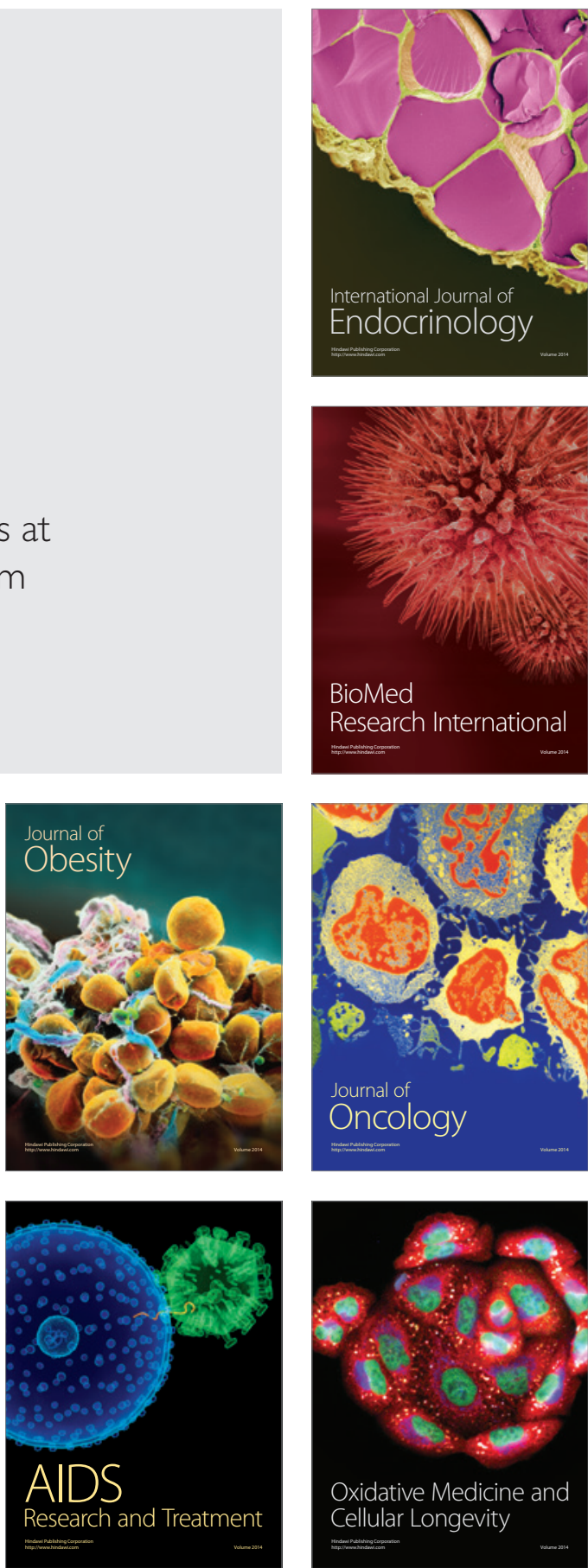